\title{
A PDP-11/45 program for playing $n$-person characteristic function games
}

\author{
JAMES P. KAHAN, ARTHUR W. COSTON, RICHARD A. HELWIG, \\ AMNON RAPOPORT, and THOMAS S. WALLSTEN \\ L. L. Thurstone Psychometric Laboratory, University of North Carolina, \\ Chapel Hill, North Carolina 27514
}

\begin{abstract}
NPER II is an on-line PDP-11/45 computer program for studying bargaining and coalition formation processes within the framework of $n$-person games in characteristic function form. The extensive vocabulary of the program and its mode of operation are presented nontechnically, followed by an examination of a protocol from a sample four-person game. Improvements over a previous version of the program and appications to other experimental paradigms investigating coalition formation and bargaining are discussed in the last two sections of the paper.
\end{abstract}

NPER II is a program written for the PDP-11/45 computer to study bargaining and coalition formation processes within the framework of $n$-person games in characteristic function form. This program is a successor to the coalitions system (Kahan \& Helwig, 1971; Rapoport \& Kahan, 1974) written for the PDP-8, which has been employed in a number of studies on bargaining and coalition formation. NPER II differs from its predecessor in that it possesses a wider game vocabulary, has better methods of game definition, data storage and retrieval, and bookkeeping, and provides options for types of games not possible previously. We shall first present a description of NPFR II, then a sample game, and shall conclude with a discussion of improvements of the new version over the old, including the generalizability of the basic paradigm that is provided by the program.

\section{PLAYING GAMES IN CHARACTERISTIC FUNCTION FORM}

An n-person game in characteristic function form is defined by specifying a number of players and a function that assigns a real number (positive integer in the present implementation) to each possible subset (coalition) of the players. This value assigned to the coalition represents the utility that its members jointly command. The object of the game is for a player to gain for himself the maximum possible utility through one of the various coalitions of which he is a member. A coalition is formed when its members agree on how to allocate its value.

When the players are seated, each at individual Teletypes in a soundproofed cubicle, NPER II starts a game by telling each player his role in the game (by a letter identification) and by printing out the values for that game. Consider an example game for four players defined by the values: $A=10, B=15, C=15, D=10$,

This research has been supported by Grant SOC74-15027 from the National Science Foundation. Kahan is now at the University of Southern California.
$\mathrm{AB}=30, \quad \mathrm{AC}=35, \quad \mathrm{AD}=25, \quad \mathrm{BD}=40, \quad \mathrm{CD}=35$, $\mathrm{ABC}=55, \mathrm{ACD}=60, \mathrm{ABD}=60, \mathrm{ABCD}=85$.

Consider this game from the point of view of Player A. Alone he can realize 10 points. If he forms a coalition with Player $B$, the two players command 30 points. Similarly, the coalitions $\mathrm{AC}$ and $\mathrm{AD}$ command 35 and 25 points together, respectively. Or, if Player A joins with both Players $\mathrm{B}$ and $\mathrm{C}$, the three command 55 points. Both coalitions $\mathrm{ACD}$ and $\mathrm{ABD}$ command 60 points. Finally, if four players combine, this grand coalltion of all the players controls 85 points. Note that Play. ers $B$ and $C$ cannot form a coalition without the presence of Player $A$. The value of coalitions $B C$ and $B C D$ are technically zero; empirically they are not allowed to form.

In NPER II, the players communicate by typing various statements about how to divide the value of a coalition among its members, in the context of a bargaining process that contains three stages. The first, or negotiation stage, is when players explore the potentrals of various coalitions. Different proposals for forming coalitions and allocating the values are made. In this stage, players gain awareness of their relative strengths and weaknesses, and of the stances and expectations of the other players. The second stage, termed the acceptance stage, begins when a set of players indicates general acceptance of a proposal. This acceptance is not binding, but does indicate that serious consideration is being given to the proposal as an outcome for that coalition. During the acceptance stage, the members of the coalition may be interested in modifications of the agreement, and the nonmembers of the coalition are interested in disrupting the proposal to further their own interests. It is in this stage that various strategies and counterstrategies may become quite subtle and complex; and for this reason, it is a psychologically interesting stage. Finally, the third, or ratification stage, terminates the bargaining process. The members of a tentative coalition have considered a proposal, have seen it through acceptance, and are now willing to make a binding com- 
mitment. If all players agree upon ratification, the coalition is formed, the players receive their payoffs, and the game is terminated for them. The entire game is terminated when each player is in one, and only one, ratified coalition.

Communication in NPER II is via a set of key words. Upon receiving a request for input from the computer, the player types a key word, followed by parameters if necessary. The computer then checks the legality of the message and transmits its content to the players who are supposed to receive it. Table 1 shows the set of key words used in NPER II, along with their required parameters and their effects on the coalitions addressed and on other coalitions.

The basic key words for bargaining are OFFER, where a player proposes an allocation of points; ACCEPT, where a player makes a tentative commitment to the allocation; and RATIFY, where a player initiates termination of the game. Indeed, it is possible to play the game with only this primitive set of three key words. Any member of a coalition may make an offer; the computer maintains each player's most recent statement regarding each coalition. To enter the acceptance stage, all members of a coalition (including the originator of the OFFER) must ACCEPT it (the originator cannot be the first to ACCEPT his own OFFER). When one player proposes RATIFY, all players in accepted coalitions immediately vote yes or no. Coalitions with unanimous consent are ratified; others are dissolved.

The key words AGREE, REJECT, and AFFIRM give shading to intentions concerning coalitions. AGREE indicates a mild liking of an OFFER and REJECT strong distaste (the proposal can simply be ignored). AFFIRM indicates a reiteration of a player's most recent stand with respect to a coalition. PASS indicates that a player has nothing to say at the present time. SOLO immediately removes a player from the game; he will take what he can get by not joining any coalition. SUGGEST is like OFFER except that (1) it is unofficial and (2) it may be sent to any players, not necessarily including all those in the proposal. REMARK and MESSAGE allow communication outside the NPER II vocabulary. The former allows free text, while the latter sends experimenterdefined standard messages. If players lose track of the proceedings, the key words VALUE and STATUS keep them up-to-date. All key words other than OFFER, ACCEPT, and RATIFY may be disabled at the experimenters option.

Figure 1 presents an example game from the point of view of Player $\mathrm{B}$. The game is an example designed to

Table 1: Key Words and Their Effects

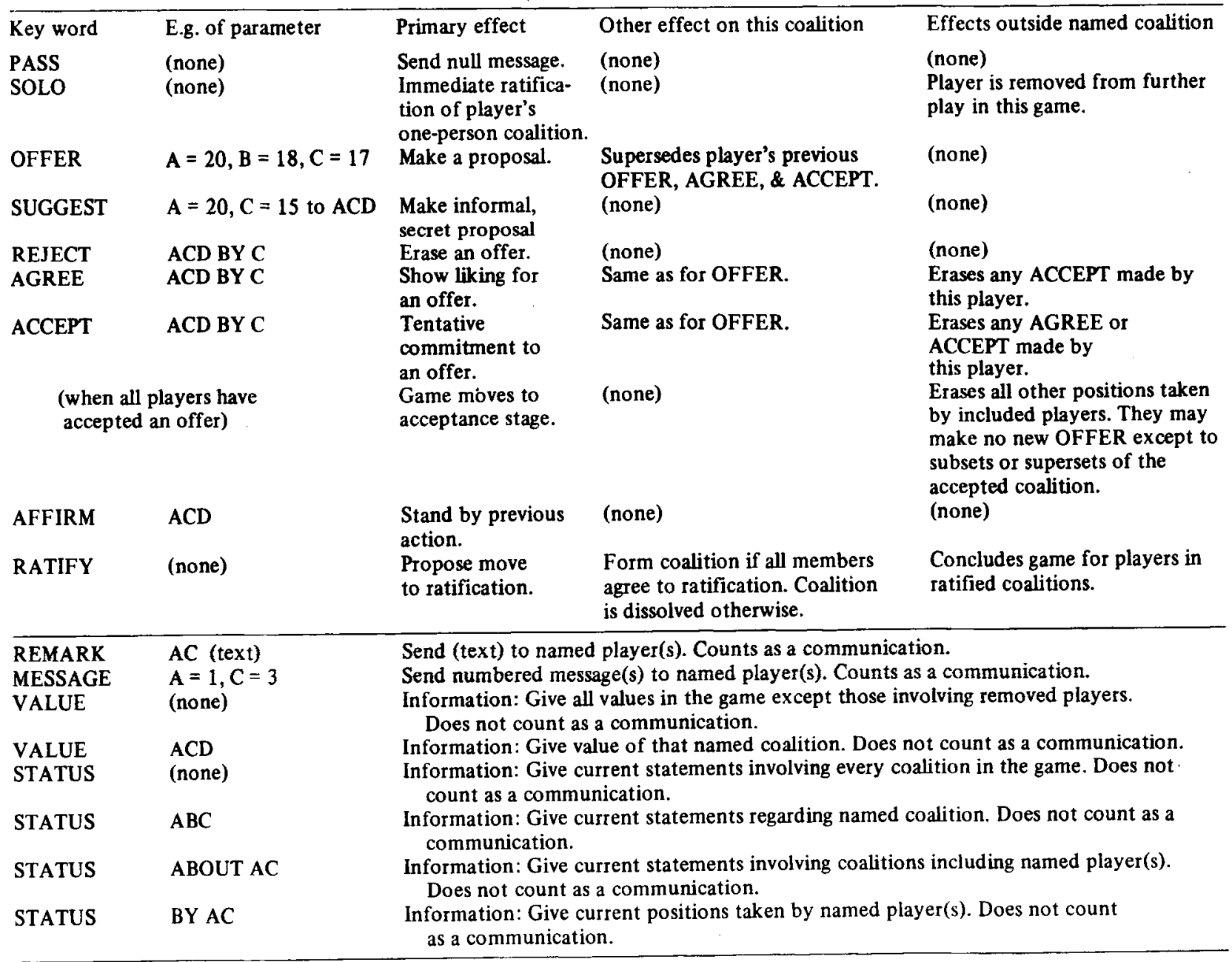



0. IN THE FOLLOWING CAME YOU ARE PLAYER B $A=10 ; \quad B=15 ; C=15 ; D=10 ; A B=30 ; A C=35 ; A D=25 ; B D=40 ; C D=35$ $A B C=55 ; A C D=60 ; A B D=60 ; A B C D=85$.

1. A OFFERS AC: $A=15 ; \quad C=20$

2. B, GO AHEAD: OFFER B=25, C-25

B, GO ABBAD: OFFER $A=25, \frac{B-25, \quad D=20}{A=25 ; B=25 ;} \quad D=10$

B OTFERS ABD:

C PASSES

D SAYS: IT I DOH'T GET A GOOD DEAL, I MAY SOLO.

A AGREES ABD BY B: $A=25 ; B=25 ; D=10$

6. B, GO AHEAD: ACGEPT ABD BY B

YOU CAHNOT ACCEPT YOUR OWI OTFER UKTIL SOMEOHS ELSE DOES

$B$, GO AHEAD: $O F E B B \quad A=20, B=20$

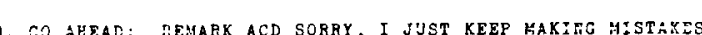

B REMARKS TO ACD: SORRY, I JUST KERP MAKTIG MISTAKES

C OFFERS ABC: $\quad A=16 ; B=17 ; C=22$

D REJECTS ABD BY B: A=25; B=25; D=10

$D$ REJECTS ABD BY B: $A=20 ; B=15 ; \quad C=20$
$A$ OFFERS ABC:

0. B, GO AREAD: OFFER $C=13, A=17, B=25$

B OFFERS ABC:
$C$ AFFIRMS HIS OFFER TO ABC: $A=16 ; \quad B=17 ; C=22$

D SOLOS AHD IS REMOVBD FROM PLAY

13. A OPFERS AB: A=13;B=17

24. B, GO AHEAD: $A=10 ; B=15 ; \quad \frac{\text { MLUE }}{C=15} ; A B=30 ; A C-35 ; A B C=55$

B, GO AHEAD: STATUS

A OPFERED AC:

C OFFERED ABC:

A OFFERED ABC:

$B$ OFTERED ABC

- SOLOED D:

A OFPERD AB:

$A=15 ; C=20$

$A=16 ; B=17 ; \quad C=22$

$A=20 ; B=15 ; C=20$

$A=17 ; \quad B=25 ; C=13$

$D=10^{\circ}$

$A=13 ; B=17$

B. GO AHEAD: $\frac{\text { SUGGST } A=15, B-22, C=12, \text { TO } A}{B \text { SUGGESTS }}$

17. D, GO AHEAD: $A G R E E$ AB BY A

17. D AGREES AB $\frac{A Y A: \quad A=13 ; B \neq 17}{B Y}$

18. C AGREES AC BY $A$ : $A=15 ; C=20$

ACCEPTS ABC BY C: A :
REPLACING HIS OWM OFFER TO ABC

20. B, GO AHEAD: STATUS

$A$ OTFERED AC: $A * 15: C=20$

C AGREED

C OTPERD $A B C$ : $\quad A=16 ; B=17 ; r=22$

B OTFERED ABC: $A=17 ; B=25 ; C=13$

A OFFERED AB:

$A=17$
$D=10$

$A=13 ; B=17$

G AGREED.

$B$, GO ABEAD: OYFBR $A=16, C=20, B=19$

B OTFER ABC: AEI : $\mathrm{B}=19 ; \mathrm{C}=20$

REPLACIIG HIS PREVIOUS OFPE

C ACCEPTB ABC BY B: $A=16 ; \quad B=29 ; C=20$

REPLACIUC HIS OWE OPFER TO ABC

AMD HIS AGRER TO A'S OPFER TO AC
$A$ ACCEPTS ABC BY B: A-16; B-19; C=20

22.

23. B, GO AHEAD: AF ABCBYB
B ACCEPTS ABC BY B: $A=16 ; B=19 ; C=20$

ACCEPTS ABC BY B:
REPLACIMG HIS AGRE TO A'B OPFB TO

ABC NOW ALL-ACCEPIED, WULLITYIBO ALL OTHER POSITIONS BY THEM

24. B, PLAYER C CALLED POR A RATIFICATIOA VOTE. DO YOU RATIFY

THE COALITIOA ABC: A=16; $B=19 ; C=20$

C CALLED FOR RATIFICATIOH

ABC VOTED TO FATITY

ABC ARI HOW IN RATIPIED COALITIOA AHD ARE REMOVED FROM IGAME OVERII

25. TODAY YOU HAVE EARED 29 POINTS

Figure 1. Player B's protocol of a four-person example game in characteristic function form. (B's typed messages are underlined.)

show various features of the program, and does not represent actual data. Except for the numbering of the statements, the figure is an exact replica of the input and output from Player B's teletypewriter. Message 0 is from the computer, and tells the player his own identity and the characteristic function for this game. Our discussion will be guided by the statement numbers in Figure 1, which correspond to moves in the play of this game.

The first move of the game is an OFFER from Player $\mathrm{A}$ to coalition $\mathrm{AC}$, in which both Players $\mathrm{A}$ and $\mathrm{C}$ receive five more points than each would by participating in no coalition. Player B moves second, and after attempting to address an illegal coalition, makes a threeperson OFFER to coalition ACD. Note that, in OFFER statements, the coalition is implied by who is named in the point allocation. Player $\mathrm{C}$ chooses to wait one round. so Statement 3 is a PASS on his part. Player D uses his move to send a MESSAGE. Player $B$ receives the message shown on his teletypewriter; he does not know if other players received similar, different, or no messages Irom Piayer D. The game continues through move 11 . showing the different types of key words and some error messages in response to Player B's errors. Note that in B's REMARK in move 6 , the computer reminds him who received his remark; other players do not receive that information.

On move 12, Player D chooses SOLO, which removes him from the game. Player $B$, on his next move (14), uses the VALUE key word to find out what coalitions remain legal in the game, and then uses STATUS to obtain a record of all current positions in the game. Note that Player B does not see moves 15 and 16; Players $\mathrm{A}$ and $\mathrm{C}$ have sent communications (SUGGEST, MESSAGE, or REMARK) to each other, but have not included him as a recipient.

In moves 17 through 23 , the players again proceed with the game, showing how the computer signals the effect of new moves on previously taken positions and demonstrating how all-accept is signaled. Finally, on move 24, Player C calls for ratification. Both Players A and $B$ vote in favor of ratification (simultaneously and independently) and, with all players now in ratified coalitions, the game terminates. As this game was the only one played in this session, the person who played $B$ is given the sessions' earnings in Statement 25.

\section{COMPUTATIONAL FEATURES}

NPER II is written for the PDP-11/45 in 11TRAN, a language resembling PL/I written at the L. L. Thurstone Psychometric Laboratory. In the program design, emphasis is placed on the subject interface; for example, the program utilizes extensive error checking and validation, dynamic key word abbreviations, and clear, concise messages in easily readable formats. Because of the large number of players allowed, as well as the total possible number of positions that could theoretically be outstanding at one time (on the order of 300,000 ), data structures are dynamically allocated from free space within the task and are inserted in appropriate linked lists. The essence of NPER II, then, is a computer program composed of a sophisticated parser, an internal structure based on linked lists, and a message formulator and printer. 


\section{IMPROVEMENTS OVER PREVIOUS VERSIONS}

As stated earlier, NPER II is a revised version of a system used extensively for the past 5 years. Perhaps an indication of the flexibility of the new program can be gained by reiterating three limitations of the previous version discussed by Rapoport and Kahan (1974), and showing how the present version overcomes these limitations.

The first constraint of the previous program was that a player could accept only one coalition at a time. In effect, the ACCEPT key word's function was too narrow. In the present version, acceptance has been broken down into AGREE and ACCEPT statements. An agreement, the weaker version, can now be made to each potential coalition of which a person is a member. Acceptance is now free to have stronger force. A player must now accept his own original offer, once others have indicated acceptance of it. That is to say, where an OFFER was once assumed to be automatically accepted by its author, now it is only assumed to be agreed to. This loosening of acceptance procedures also allows the program to be expanded so that each player's most recent OFFER to a coalition is outstanding, rather than just one OFFER per coalition. Thus, particularly in coalitions of size greater than two, the range of possibilities for a player is considerably expanded.

A second limitation of the previous game was that a ratification of a coalition of a subset of players changed the game, as coalitions with members of that subset were then not available to the remaining players. Thus, only the first coalition ratified could be used as a test of any particular model which assumes simultaneous ratification. In the present version, the experimenter may lock out ratification for an unlimited time, until all players are in accepted coalitions. A single ratification statement then serves all accepted coalitions at once, instead of only those players in a particular accepted coalition.

A third limitation was that only one issue could be negotiated at a time. As present, research trends in the areas of bargaining and decision making indicate increased interest in multi-attribute environments; NPER II has been constructed to play with up to three issues (each specified by its own characteristic function) being negotiated simultaneously. In the multi-attribute version, the issues are named by the experimenter (typically with color names), and the player must specify, in addition to his key word, which issue he wants to address with his message. Thus, an agreement in this version might read: BLUE AGREE ABC BY B. Here a player agrees to the proposal to coalition $A B C$ made by Player B, in the issue labeled "blue."

\section{APPLICABILITY}

NPER II can accommodate all of the research done using the previous system. Coalitions was used in the in- vestigation of games in characteristic function form for three players, both with (Rapoport \& Kahan, 1975; Medlin, Note 1) and without (Kahan \& Rapoport, 1974, 1975) three-person coalitions, and varieties of fourperson games (Funk, 1972; Horowitz \& Rapoport, 1974). By simple extension, other work directly investigating $n$-person games in characteristic function form (e.g., Buckley \& Westen, 1973; Maschler, 1965; Riker, 1967; Selten \& Schuster, 1968) could be run using NPER II.

In our usage, subjects are paid a linear function of the points they earn. However, by employing special payoff transformations, other experiments that are not already in NPER II format could be replicated. Laing and Morrison (1974) have studied games of status, where a player's payoff depends not on the absolute number of points he has, but rather on the rank order of his total among the totals of all participating players. Their experiments could be replicated by using their characteristic functions as originally presented, but by rewarding subjects on the basis of rank order rather than on absolute quantity.

Much of the social psychological work on coalition formation has used the "Pachisi" paradigm (Caplow, 1968) pioneered by Vinacke and Arkoff (1957). In many of these studies, interest focused on a game where players could combine weights of four, three, and two in a majority-rule constant-sum game. This classical game could be played in NPER II format by using the following characteristic function: $A=1, B=0, C=0$, $\mathrm{AB}=700, \mathrm{AC}=600, \mathrm{BC}=500, \mathrm{ABC}=900$. The values to the multiperson coalitions represent the 4-3.2 weights multiplied by 100 . The values to the one-person coalitions represent the fact that, if no coalition forms, Player A (with the largest weight) wins the game. The multiplicative factor of 100 is to round Player A's payoff to zero if coalition BC forms. Subjects are paid a constant sum, which is split in proportion to the points each has at the end of the NPER II game. Such a technique would allow a test of the social psychological hypotheses without the confounding of restricted communication and the artificial separation of payoff and coalition formation that characterize most of the Pachisi studies.

\section{REFERENCE NOTE}

1. Medlin, S. Effects of grand coalition payoffs on caalition formation in three-person games. Unpublished manuscript, 1975.

\section{REFERENCES}

BuCKLEY, J. J., \& Westen, T. E. The symmetric solution tō a five-person constant-sum game as a description of experimental game outcomes. Journal of Conflict Resolution, 1973, 17, 703-718.

CAPlow, T. Two against one coalitions in triads. Englewood Cliffs, N. J: Prentice-Hall, 1968. 
FLNK. S. G. Value power and positional power in n-person games. Unpublished MA thesis, Chapel Hill: University of North Carolina. 1972.

Horowitz, A. D., \& Rapoport, AM. Test of the kernel and two bargaining set models in four- and five-person games. In An. Rapoport (Ed.). Game theory as a theory of conflict resolution. Dordrecht. Holland: Reidel, 1974. Pp.161-192.

Kahan, J. P., \& Helwig, R. A. Coalitions: A system of programs for computer-controlled bargainıng games. General Systems, $19^{7} 1$ 16, 31-41.

KahAN, J. P., \& RAPOPORT, AM. Test of the bargaining set and kernel models in three-person games. In An. Rapoport (Ed.), Game theory as a theory of conflict resolution. Dordrecht. Holland. Reidel. 1974. Pp. 119-160.

Kahan. J. P. \& Rapoport. AM. The effect of singleperson redlu's on bargatming and coaltuon formation in threeperson cooperatve games. Report No. 139 Chapel Huil, N.C: L. L. Thurstone Psychometric Laboratory, July 1975.

LAING, J. D., \& Morrison, R. J. Sequential games of status. Behavtoral Scaence, 1974, 19, $1^{77}-196$.

Maschler, M. Playing an n-person game An experiment. Economic Research Program Research Memorandum No. 73. Princeton. N.J: Princeton University, 1965.

Rapoport, Am. \& KaHAN, J. P. Computer controlled research on bargaining and coaltion formation. Behavior Research Methods \& Instrumentation, 1974, 6, 8793.

RAPOPORT. AM. \& Kahan. J. P. Two- and three person coalitions in experimental three-person cooperative games. Report No. 137. Chapel Hill, N.C. L. L. Thurstone Psychometric Laboratory, Apr11 $19^{75}$

Riker, W. H. Bargatining in a three-person game. American Poltucal Sclence Reve'w: 1967, 61, 642-656.

Seltfon, R., \& Schuster. K. G. Psychological variables and coalition forming behavior. In K. Borch \& J. Mossin (Eds.), Risk and uncertainty London: Macmillan, 19h8

VINACKE. W. F, \& ARKoff, A An experimental situd of coalutions in the triad American Socological Reverw $1957,22,406 \cdot 415$ 